\title{
Local Surgery Improves Survival in Patients with Primary Metastatic Breast Cancer: A Population-Based Study
}

\author{
Yuan-Yuan Zhao a,b He-Fen Sun ${ }^{a, b} \quad$ Xue-Li Yang ${ }^{a, b} \quad$ Yang Zhao $^{a, b}$ \\ Meng-Ting Chen ${ }^{a, b}$ Wei Jin ${ }^{a, b}$ \\ ${ }^{a}$ Department of Breast Surgery, Key Laboratory of Breast Cancer in Shanghai, Fudan University Shanghai Cancer \\ Center, Shanghai, China; ${ }^{\mathrm{b}}$ Department of Oncology, Shanghai Medical College, Fudan University, Shanghai, China
}

\section{Keywords}

Primary metastatic breast cancer - Local surgery · Survival rate $\cdot$ SEER database

\begin{abstract}
The clinical value of local surgery in the breast cancer patients with distant metastasis is still unclear. A total of 8,922 primary metastatic breast cancer patients from the Surveillance, Epidemiology, and End Results (SEER) database were analyzed in the current study. Primary outcome variables included breast cancer-specific survival (BCSS) and overall survival (OS). Among the patients, 1,724 (19.3\%) who underwent surgical treatment (ST) of primary breast tumor had increased OS $(p<0.001)$ and BCSS $(p<0.001)$ compared with those in the nonsurgical treatment (NST) group. Multivariate analysis revealed that surgery improved survival and was an independent prognostic factor for OS (hazard ratio $[\mathrm{HR}]=$ $0.617 ; 95 \%$ confidence interval $[\mathrm{Cl}], 0.562-0.676, p<0.001)$ and $\mathrm{BCSS}(\mathrm{HR}=0.623 ; 95 \% \mathrm{Cl}, 0.565-0.686, p<0.001)$. Further result showed that ST tended to prolong the survival of patients with 1 or 2 distant metastatic sites ( $p<0.05$ for OS, $p<0.05$ for BCSS). However, no differences were found in prognostic outcomes between different surgical procedure groups ( $p=0.886$ for OS, $p=0.943$ for BCSS). In conclusion, our study suggested that local surgery appeared to confer a survival benefit, which may provide new understanding of treatment for these patients.

(c) 2019 S. Karger AG, Basel
\end{abstract}

\section{Introduction}

Breast cancer is one the most frequently occurring malignancies $[1,2]$. In the United States, 1 in 8 women will develop breast cancer in her lifetime [3]. An epidemiological study predicted approximately 3.2 million new cases per year by 2050 [4]. However, approximately $10 \%$ of breast cancer patients had distant metastases at initial presentation, which was associated with poor outcome and considered to be incurable [5]. Indeed, distant metastasis was the main cause of mortality among breast cancer patients and should be given more attention [6]. Although systemic palliative treatment can prolong the survival of primary metastatic breast cancer (PMBC) patients, the expected survival is still unsatisfactory.

Several retrospective studies demonstrated that local surgery of the primary tumor had a positive impact on the survival of patients diagnosed with PMBC [7-10]. However, the role of local surgery in PMBC is still controversial. Some studies showed that tumor removal did not bring significant survival benefit [11-15]. However, other researchers found that local treatment would prolong survival in specific groups of patients $[16,17]$. So far, there has been no consensus on the efficacy of local sur-

Yuan-Yuan Zhao and He-Fe Sun have contributed equally to this work. 
Table 1. Characteristics of breast cancer patients with distant metastases from the SEER database

\begin{tabular}{|c|c|c|c|c|c|c|c|c|}
\hline \multirow[t]{2}{*}{ Characteristic } & & \multicolumn{2}{|l|}{ All } & \multicolumn{2}{|l|}{ ST } & \multicolumn{2}{|l|}{ NST } & \multirow[t]{2}{*}{$p$ value } \\
\hline & & $n=8,922$ & $\%$ & $n=1,724$ & $\%$ & $n=7,198$ & $\%$ & \\
\hline Age & $\begin{array}{l}<35 \text { years } \\
35-60 \text { years } \\
>60 \text { years }\end{array}$ & $\begin{array}{r}276 \\
3,801 \\
4,845\end{array}$ & $\begin{array}{r}3.1 \\
42.6 \\
54.3\end{array}$ & $\begin{array}{r}82 \\
833 \\
809\end{array}$ & $\begin{array}{r}4.8 \\
48.3 \\
46.9\end{array}$ & $\begin{array}{r}194 \\
2,968 \\
4,036\end{array}$ & $\begin{array}{r}2.7 \\
41.2 \\
56.1\end{array}$ & $<0.001$ \\
\hline Race & $\begin{array}{l}\text { White } \\
\text { Black } \\
\text { Others } \\
\text { Unknown }\end{array}$ & $\begin{array}{r}6,722 \\
1,525 \\
624 \\
51\end{array}$ & $\begin{array}{c}75.3 \\
17.1 \\
7 \\
0.5\end{array}$ & $\begin{array}{r}1,287 \\
285 \\
144 \\
8\end{array}$ & $\begin{array}{r}74.7 \\
16.5 \\
8.4 \\
0.5\end{array}$ & $\begin{array}{r}5,435 \\
1,240 \\
480 \\
43\end{array}$ & $\begin{array}{r}75.5 \\
17.2 \\
6.7 \\
0.6\end{array}$ & 0.086 \\
\hline Grade $^{b}$ & $\begin{array}{l}1 \\
2 \\
3 \\
\text { Undifferentiated } \\
\text { Unknown }\end{array}$ & $\begin{array}{r}477 \\
2,621 \\
3,141 \\
72 \\
2,611\end{array}$ & $\begin{array}{r}5.3 \\
29.4 \\
35.2 \\
0.8 \\
29.3\end{array}$ & $\begin{array}{r}91 \\
513 \\
947 \\
18 \\
155\end{array}$ & $\begin{array}{r}5.3 \\
29.8 \\
54.9 \\
1 \\
9\end{array}$ & $\begin{array}{r}386 \\
2,108 \\
2,194 \\
54 \\
2,456\end{array}$ & $\begin{array}{r}5.4 \\
29.3 \\
30.5 \\
0.8 \\
34.1\end{array}$ & $<0.001$ \\
\hline T stage & $\begin{array}{l}\mathrm{T}_{1} \\
\mathrm{~T}_{2} \\
\mathrm{~T}_{3} \\
\mathrm{~T}_{4} \\
\mathrm{~T}_{\mathrm{X}}\end{array}$ & $\begin{array}{l}1,026 \\
2,139 \\
1,187 \\
2,764 \\
1,806\end{array}$ & $\begin{array}{l}11.5 \\
24 \\
13.3 \\
31 \\
20.2 \\
\end{array}$ & $\begin{array}{r}209 \\
591 \\
324 \\
510 \\
90\end{array}$ & $\begin{array}{r}12.1 \\
34.3 \\
18.8 \\
29.6 \\
5.2 \\
\end{array}$ & $\begin{array}{r}817 \\
1,548 \\
863 \\
2,254 \\
1,716 \\
\end{array}$ & $\begin{array}{l}11.4 \\
21.5 \\
12 \\
31.3 \\
23.8\end{array}$ & $<0.001$ \\
\hline $\mathrm{N}$ stage & $\begin{array}{l}\mathrm{N}_{0} \\
\mathrm{~N}_{1} \\
\mathrm{~N}_{2} \\
\mathrm{~N}_{3} \\
\mathrm{~N}_{\mathrm{X}}\end{array}$ & $\begin{array}{r}2,016 \\
3,685 \\
829 \\
1,101 \\
1,291 \\
\end{array}$ & $\begin{array}{r}22.6 \\
41.3 \\
9.3 \\
12.3 \\
14.5 \\
\end{array}$ & $\begin{array}{r}323 \\
627 \\
314 \\
378 \\
82 \\
\end{array}$ & $\begin{array}{r}18.7 \\
36.4 \\
18.2 \\
21.9 \\
4.8 \\
\end{array}$ & $\begin{array}{r}1,693 \\
3,058 \\
515 \\
723 \\
1,209 \\
\end{array}$ & $\begin{array}{c}23.5 \\
42.5 \\
7.2 \\
10 \\
16.8\end{array}$ & $<0.001$ \\
\hline Breast subtype ${ }^{c}$ & $\begin{array}{l}\text { HER2+/HR+ } \\
\text { HER2+/HR- } \\
\text { HER2-/HR+ } \\
\text { HER2-/HR- }\end{array}$ & $\begin{array}{r}1,206 \\
662 \\
6,027 \\
1,027 \\
\end{array}$ & $\begin{array}{r}13.5 \\
7.4 \\
67.6 \\
11.5 \\
\end{array}$ & $\begin{array}{l}279 \\
173 \\
965 \\
307 \\
\end{array}$ & $\begin{array}{l}16.2 \\
10 \\
56 \\
17.8 \\
\end{array}$ & $\begin{array}{r}927 \\
489 \\
5,062 \\
720 \\
\end{array}$ & $\begin{array}{r}12.9 \\
6.8 \\
70.3 \\
10 \\
\end{array}$ & $<0.001$ \\
\hline Radiation & $\begin{array}{l}\text { Yes } \\
\text { No } \\
\text { Unknown }\end{array}$ & $\begin{array}{r}1,861 \\
6,840 \\
221 \\
\end{array}$ & $\begin{array}{r}20.9 \\
76.9 \\
2.5 \\
\end{array}$ & $\begin{array}{r}8 \\
1,594 \\
122 \\
\end{array}$ & $\begin{array}{r}0.5 \\
92.5 \\
7.1 \\
\end{array}$ & $\begin{array}{r}1,853 \\
5,246 \\
99\end{array}$ & $\begin{array}{r}25.7 \\
72.9 \\
1.4\end{array}$ & $<0.001$ \\
\hline Number of sites & $\begin{array}{l}1 \\
2 \\
>2 \\
\text { Unknown }\end{array}$ & $\begin{array}{r}4,442 \\
2,051 \\
784 \\
1,645\end{array}$ & $\begin{array}{l}49.8 \\
23 \\
8.8 \\
18.4\end{array}$ & $\begin{array}{r}1,035 \\
262 \\
59 \\
368\end{array}$ & \begin{tabular}{r}
\multicolumn{1}{c}{60} \\
15.2 \\
3.4 \\
21.3
\end{tabular} & $\begin{array}{r}3,407 \\
1,789 \\
725 \\
1,277\end{array}$ & $\begin{array}{l}47.3 \\
24.9 \\
10.1 \\
17.7\end{array}$ & $<0.001$ \\
\hline
\end{tabular}

HER2, human epidermal growth factor receptor-2; HR, hormone receptor. ${ }^{\text {a }}$ Other races include American Indian, Alaska Native, Asian and Pacific Islanders. ${ }^{\mathrm{b}}$ Grade 1: well differentiated; grade 2: moderately differentiated; grade 3: poorly differentiated.

gery in metastatic breast cancer patients and the specific type of patients who may benefit most from it.

New understanding of heterogeneity in breast cancer has led to advanced therapeutic strategies for stage IV breast cancer in the past decades. The purpose of this study is to illustrate the impact of local surgery on survival in patients diagnosed with $\mathrm{PMBC}$ using a large population-based cancer database.

\section{Methods}

Surveillance, Epidemiology, and End Results Database

Patients were identified from the Surveillance, Epidemiology, and End Results (SEER) database. The SEER database is derived from a large population-based collaboration program conducted by the
National Cancer Institute. It encompasses population-based registries containing $28 \%$ of the American population and maintains a record of demographics, tumor site, pathology, grade, stage, and treatments. Because the mortality statuses of the cases are represented, survival time can be accurately acquired. The SEER research data files were downloaded using the reference number 11443-Nov2015. The data released by the SEER database and the research following it do not require informed patient consent and ethics approval.

\section{Patients}

Cases were identified as any patients with stage IV breast cancer at the time of diagnosis from 2010 to 2013 using the SEER database. Only breast cancer patients with distant metastasis by radiographic or pathological examination were analyzed in this study. Patients with stage IV breast cancer before 2010 or after 2013 were excluded because of the incomplete information of distant metastatic sites, molecular subtypes, and the insufficient follow-up time. 


\section{Statistical Methods}

The data of patients' demographic and clinicopathological characteristics were collected as follows: age, race, grade, tumor stage, nodal status, breast subtype, surgery, and radiation. These characteristics were compared with Pearson's test. Accounting for the potential selection bias of the two groups, we developed a subgroup analysis using the propensity score matching (PSM) method to minimize them. Variables included were age and molecular subtype. The matching algorithm we chose was the nearest neighbor algorithm, using a caliper value of 0.1 SD. Primary outcome variables included breast cancer-specific survival (BCSS) and overall survival (OS). The endpoint OS was defined as the time from diagnosis to death due to any cause, and BCSS referred to the time from diagnosis to death due to breast cancer. The Kaplan-Meier method was used to analyze the survival, and the curves were compared by the log-rank test. Cox regression analysis was used to identify factors independently associated with OS and BCSS. All statistical analyses were performed with SPSS 23.0 software package or GraphPad Prism 6. A $p$ value $<0.05$ was considered significant.

\section{Results}

\section{Demographics and Clinical Characteristics of \\ Metastatic Breast Cancer Patients}

A total of 8,922 patients with metastatic breast cancer were identified in this study. Patient characteristics are listed in Table 1. The median age at diagnosis was 62.4 years, and the overall median follow-up time was 22 months. Among the patients, 1,724 (19.3\%) underwent surgical treatment (ST), while others $(80.7 \%)$ were assigned to the nonsurgical treatment (NST) group. Patients with ST tended to be younger and were more likely to have poorly/undifferentiated tumor grade, smallersized tumor, lower nodal stage, and fewer metastatic sites. However, no differences were observed between races (all $p<0.001)$.

\section{Comparison of OS and BCSS between the ST and NST Groups}

As shown in Figure 1, ST patients presented markedly better OS $(p<0.001)$ and BCSS $(p<0.001)$ than NST patients. To minimize the potential selection bias in the primary dataset, we performed a PSM analysis. After PSM, the survival of ST patients was still significantly better than that of NST patients (online suppl. Fig. 1; see www.karger.com/doi/10.1159/000503336 for all online suppl. material). In addition, as shown in online supplementary Figure 2, we found that local surgery could prolong the survival of PMBC patients with one metastatic site, regardless of the metastasis site (bone metastasis only, brain metastasis only, liver metastasis only, or lung metastasis only). After comparing the survival rates of 1,2 , and more than 2 distant metastatic sites between the ST and NST groups, the results demonstrated that patients with 1 or 2 distant metastat-

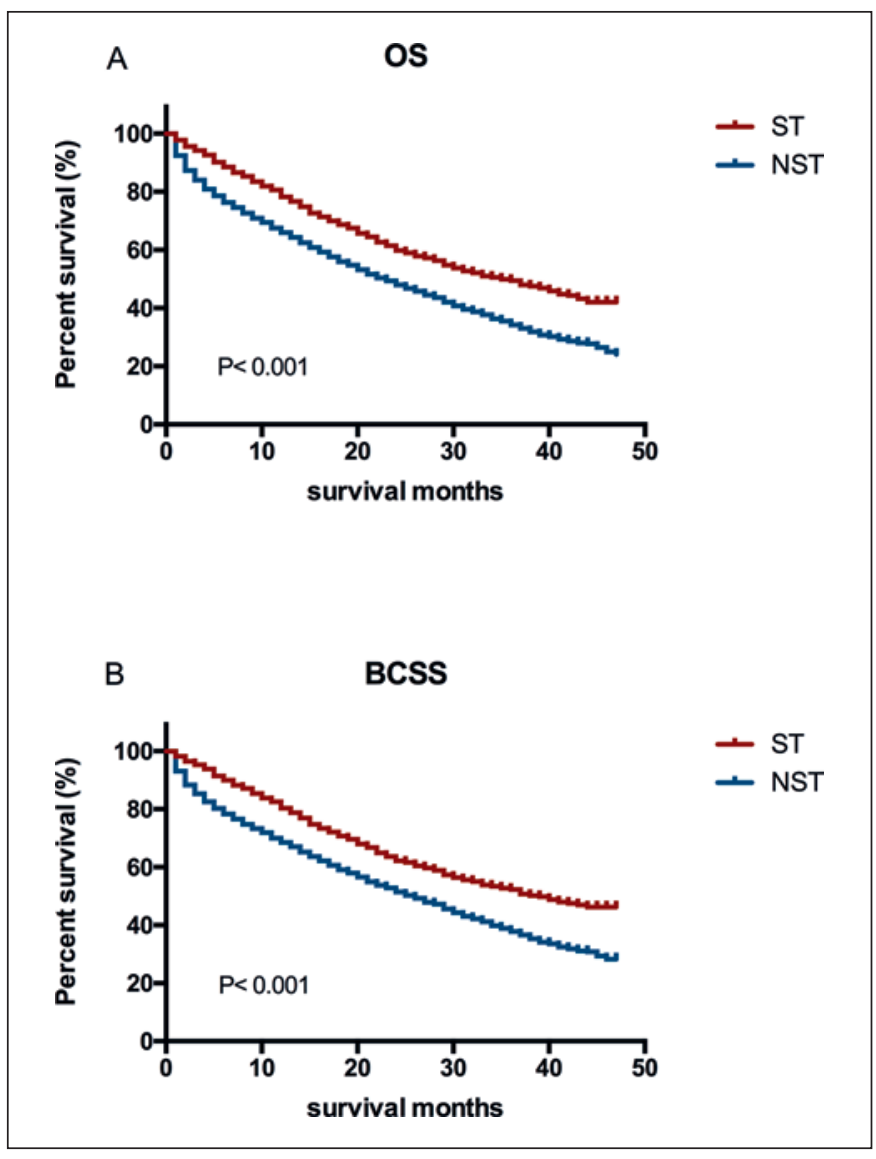

Fig. 1. Overall survival (OS) (A) and breast cancer-specific survival (BCSS) (B) of primary metastatic breast cancer patients in the surgical treatment (ST) and nonsurgical treatment (NST) groups.

ic sites could benefit from local surgery, while there was no difference between the groups in the prognosis of patients with 3 or more sites (Fig. 2). Interestingly, we found that human epidermal growth factor receptor 2 (HER2)-positive patients with 3 or more distant metastatic sites who underwent local surgery had a better outcome compared with the NST group, but ST did not prolong survival in HER2-negative patients (Fig. 3). In addition, we conducted survival analysis in ST patients with 1 or 2 distant metastatic sites according to surgical procedures (Fig. 4). No differences were found in survival outcomes between the partial mastectomy group and the modified radical mastectomy group $(p=0.886$ for OS, $p=0.943$ for BCSS).

\section{Risk Factors Associated with Survival}

Risk factors associated with survival were performed by multivariable Cox regression analysis with adjustment for potential confounders. As shown in Table 2, patients with younger age $(p<0.001)$, fewer metastatic sites $(p<$ $0.001)$, and HER $2+/ \mathrm{HR}+(p<0.001)$ revealed a trend of better survival. 

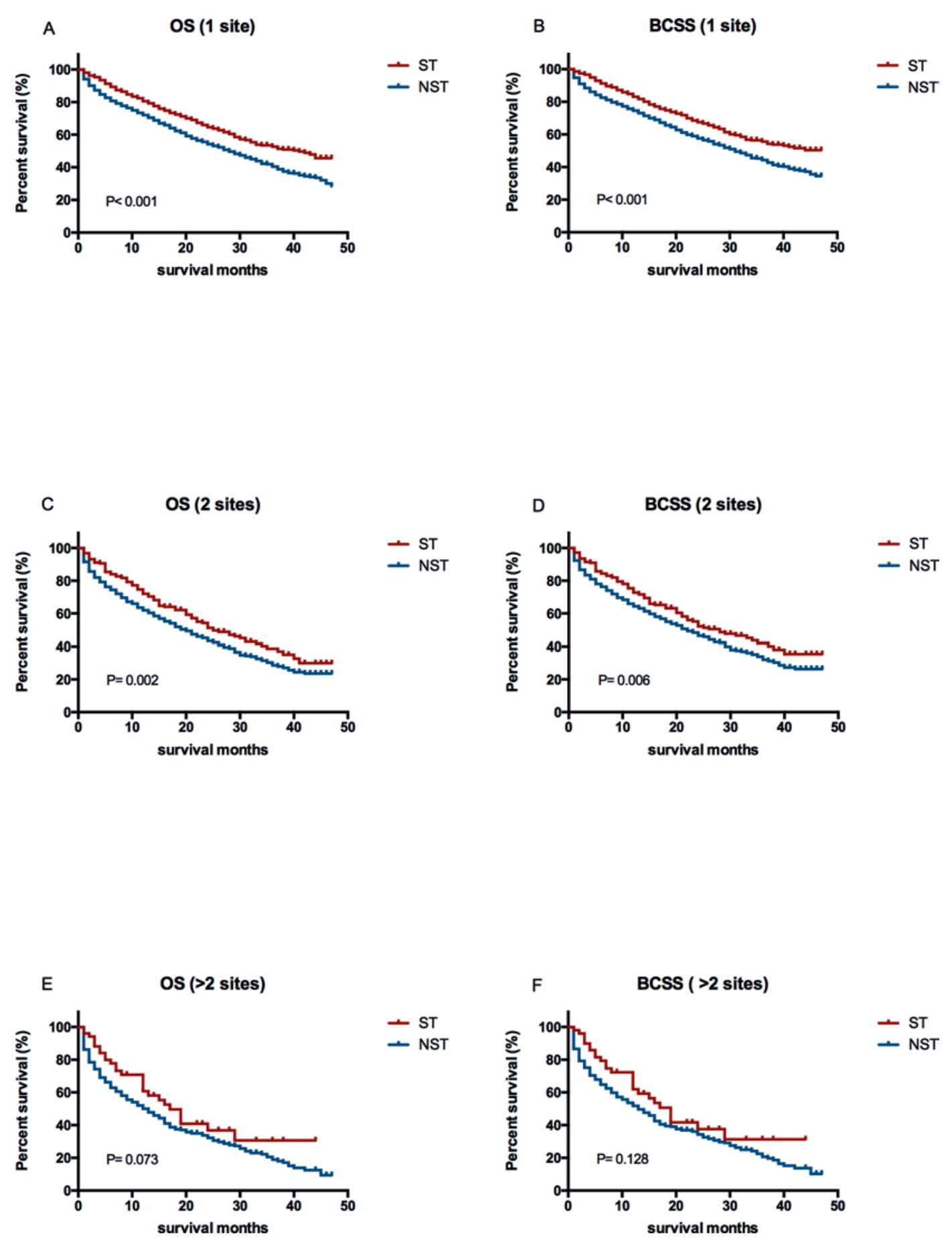

Fig. 2. Impact of surgery on overall survival (OS) and breast cancer-specific survival (BCSS) of primary metastatic breast cancer patients in the surgical treatment (ST) and nonsurgical treatment (NST) groups according to the number of metastatic sites: 1 site (A, B); 2 sites (C, D); more than 2 sites (E, F).

\section{Discussion}

The role of local ST for breast cancer patients with distant metastasis has been debated for years. In this large multipopulation-based study, we sought to identify the efficacy of local surgery on PMBC patients. The results sug- gested that after stratifying patients into 3 groups (1 metastatic site, 2 metastatic sites, and more than 2 metastatic sites), patients with 1 or 2 distant metastatic sites tended to benefit from local surgery. However, an unexpected finding of our study revealed that HER2-positive patients with more than 2 metastatic sites in the ST group had better 


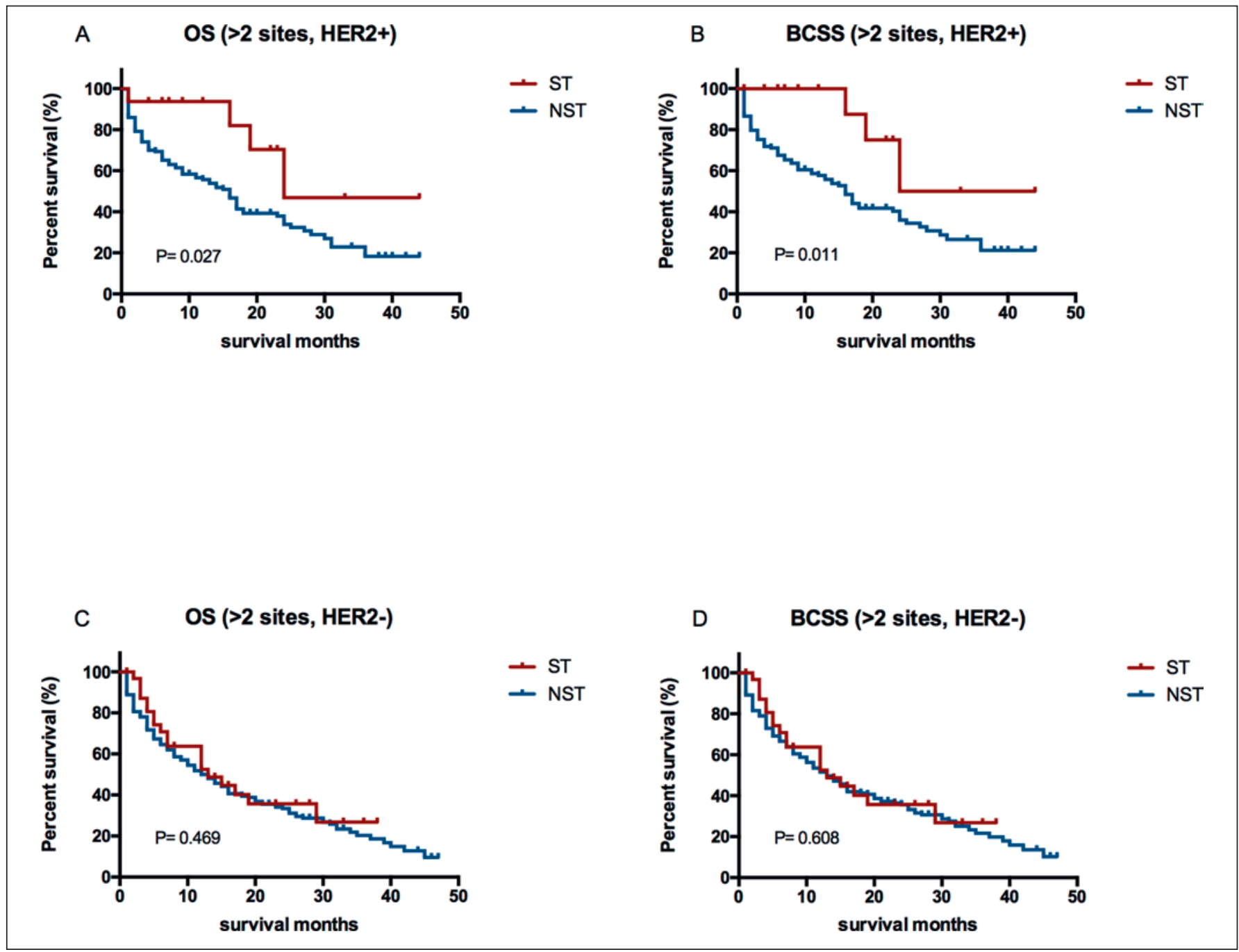

Fig. 3. Impact of surgery on overall survival (OS) and breast cancer-specific survival (BCSS) of primary metastatic breast cancer patients in the surgical treatment (ST) and nonsurgical treatment (NST) groups according to HER2 status among those with more than 2 metastatic sites. A, B HER2+ patients. C, D HER2- patients.

Table 2. Multivariate analysis of overall survival (OS) and breast cancer-specific survival (BCSS) in the study

\begin{tabular}{|c|c|c|c|c|c|}
\hline & & \multicolumn{2}{|l|}{ OS } & \multicolumn{2}{|l|}{ BCSS } \\
\hline & & HR & $p$ & HR & $p$ \\
\hline Age & $\begin{array}{l}<35 \text { years } \\
35 \sim 60 \text { years } \\
>60 \text { years }\end{array}$ & $\begin{array}{l}\text { Ref. } \\
1.47(1.16-1.89) \\
2.46(1.93-3.14)\end{array}$ & $<0.001$ & $\begin{array}{l}\text { Ref. } \\
1.47(1.14-1.89) \\
2.35(1.83-3.02)\end{array}$ & \\
\hline Breast subtype & $\begin{array}{l}\text { HER2+/HR+ } \\
\text { HER2+/HR- } \\
\text { HER2-/HR+ } \\
\text { HER2-/HR- }\end{array}$ & $\begin{array}{l}\text { Ref. } \\
1.41(1.21-1.64) \\
1.50(1.36-1.67) \\
2.87(2.54-3.24)\end{array}$ & $<0.001$ & $\begin{array}{l}\text { Ref. } \\
1.37(1.17-1.61) \\
1.48(1.33-1.64)\end{array}$ & \\
\hline Number of sites & $\begin{array}{l}1 \\
2 \\
>2\end{array}$ & $\begin{array}{l}\text { Ref. } \\
1.53(1.42-1.64) \\
2.35(2.12-2.59)\end{array}$ & $<0.001$ & $\begin{array}{l}\text { Ref. } \\
1.59(1.47-1.72) \\
2.49(1.25-2.76)\end{array}$ & \\
\hline
\end{tabular}

HER2, human epidermal growth factor receptor-2; HR, hormone receptor. 


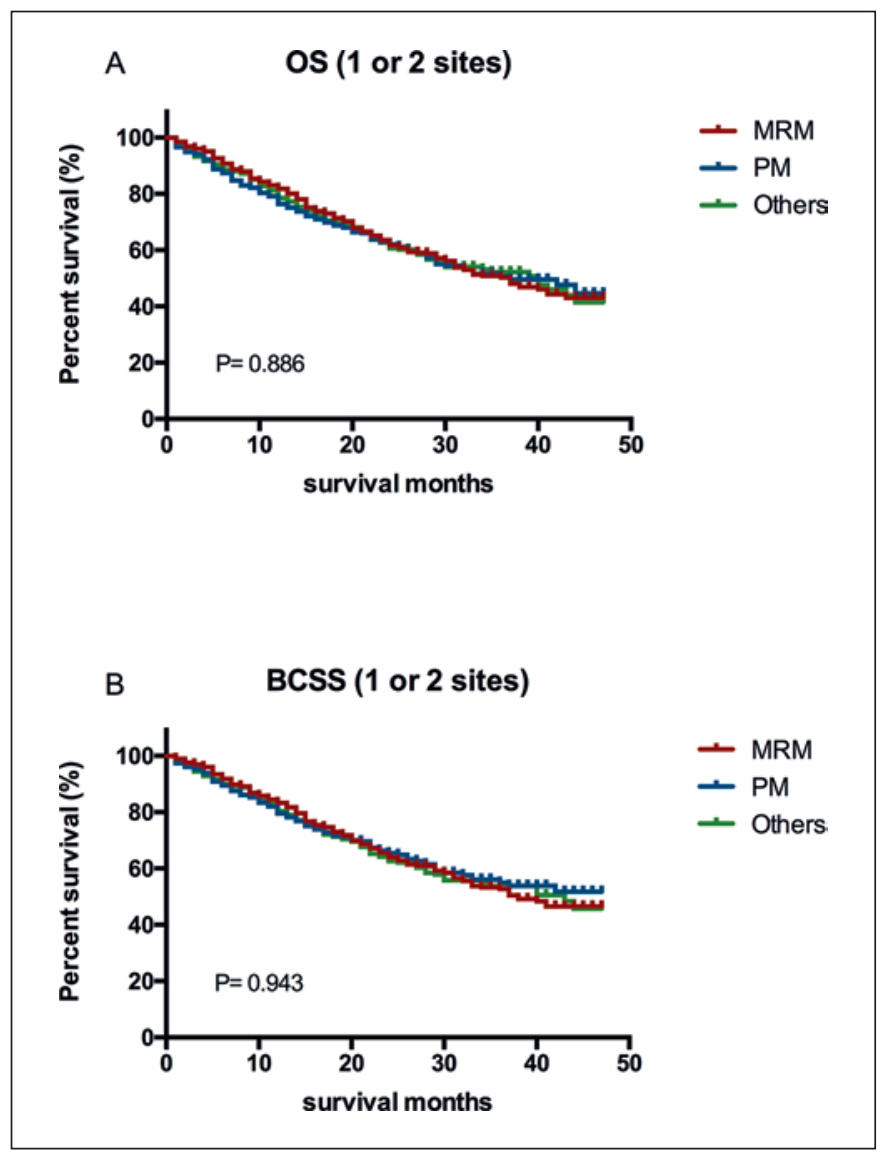

Fig. 4. Impact of surgical procedures on overall survival (OS) (A) and breast cancer-specific survival (BCSS) (B) of primary metastatic breast cancer patients with 1 or 2 metastatic sites. MRM, modified radical mastectomy; PM, partial mastectomy.

outcomes according to a subset analysis. Moreover, we analyzed the prognosis of ST patients ( 1 or 2 distant metastatic sites) with different surgical procedures, and the results indicated that resection scope did not affect survival. This study is one of the most comprehensive studies to elucidate the value of surgery and explore which kind of patients may benefit from local treatment in a large population. We hope to provide deep insight for better understanding of surgery in primary stage IV breast cancer.

Breast cancer is the most commonly diagnosed malignant carcinoma and the leading cause of death from cancer in women worldwide. Among breast cancer patients, 3-8\% have distant metastases at the time of diagnosis. Endocrine therapy according to hormone receptor status, systemic chemotherapy, target therapy based on HER2 status, and immunotherapy is recommended for primary stage IV breast cancer patients by the National Comprehensive Cancer Network guidelines [18]. The primary goals of local surgery are the prevention and the control of symptoms, such as skin ulceration and bleeding [19]. Despite the ability of systemic therapy to prolong survival, resistance to chemotherapy and hormone therapy ultimately develops.
On the other hand, decreasing tumor burden through cytoreductive surgery or radiation improves survival in several malignancies, such as colon cancer, ovarian cancer, and renal cell carcinoma [20,21]. Meanwhile, an increasing number of scientific research studies have shed new light on the heterogeneity of breast cancer and the treatment strategy, which has prompted physicians to investigate the effect of aggressive local surgery on clinical outcomes of metastatic breast cancer [22, 23].

A number of institutional and registry-based studies have emerged in the past years, which have focused on the character of local surgery therapy for metastatic breast cancer patients. Some demonstrated that surgical removal of the primary tumor would improve survival, as Ruiterkamp et al. [9] reported in a previous study. The results suggested that the median survival of the patients who had surgery of their primary tumor was significantly longer than in the patients who did not have surgery (31 vs. 14 months). Blanchard et al. [24] pointed out that ST remained an independent factor associated with improved survival after adjustment for more favorable disease characteristics in those who received surgery. Furthermore, a meta-analysis showed that surgery of the primary tumor in stage IV breast cancer appeared to offer a survival benefit in metastatic patients [25]. Besides, a meta-analysis by Headon et al. [26] also suggested that primary tumor resection may improve survival in stage IV breast cancer patients. But limitations of most studies should be noted in the interpretation of inherent bias in patients, regardless of the limited number of patients and follow-up time. More importantly, there is a dearth of literature illustrating the appropriate patient type for surgical removal. For example, the work by Rapiti et al. [27] suggested that complete surgical excision of the primary tumor improved survival of patients with metastatic breast cancer at diagnosis, particularly among women with only bone metastasis, while Blanchard et al. [24] had a different opinion on the value of surgery in breast cancer patients with only bone metastasis. These conflicting findings remind us to be cautious about this question. Several well-designed prospective randomized trials have been undertaken to obtain more convincing results. The trial conducted by the TATA Memorial Center of India demonstrated that there was a significant benefit in terms of local relapse-free survival (2 years, 84 vs. $38 \%$; $p<$ 0.001 ) with locoregional treatment, while no benefit for OS has been observed thus far ( 2 years, 42 vs. $43 \%$; $p=$ 0.79) [28]. However, the patients in this trial had an age limit of 65 years, and most had unresectable tumors.

In our study, 19.3\% of patients with PMBC underwent local surgery. The findings demonstrated that there were significant differences in OS ( 35 vs. 23 months, $p<0.001$ ) and BCSS ( 39 vs. 26 months, $p<0.001$ ) between the ST and NST groups, which was in accordance with some pre- 
vious studies. Nevertheless, does surgical excision remain valuable with an increasing number of distant metastatic sites? To find the specific patient type who may benefit most from local surgery, we analyzed the survival rates according to the different number of distant metastatic sites, including 1 site, 2 sites, and more than 2 sites. The result showed that patients with 1 or 2 distant metastatic sites who underwent surgery had longer BCSS $(p<0.05)$ and OS $(p<0.05)$ than those without surgery. No differences in BCSS $(p=0.128)$ or OS $(p=0.073)$ were found in the patients with more than 2 distant metastatic sites between the ST and NST groups. HER2 status is widely used to evaluate prognosis, predict treatment effects, and guide therapy. Interestingly, a further finding showed that HER2-positive patients with more than 2 distant metastatic sites who underwent local surgery had an obviously better outcome compared with the NST group ( $p=$ 0.027 for OS; $p=0.011$ for BCSS), but survival analysis revealed no differences in HER2-negative patients ( $p=$ 0.469 for OS; $p=0.608$ for BCSS). This outcome may be associated with the combination of anti-HER2 therapy. Whether ST can result in better prognosis independently in these patients should be scientifically substantiated by prospective trials. In addition, we conducted survival analysis in ST patients with 1 or 2 distant metastatic sites according to surgical procedure, and the result indicated that modified radical mastectomy or partial mastectomy did not affect BCSS ( $p=0.943)$ or OS $(p=0.886)$, suggesting that a larger surgical range would not improve survival of these stage IV patients. Previously, Khan et al. [13] noted that women treated with surgical resection with free margins, when compared with those not surgically treated, had superior prognosis, with a hazard ratio of 0.61 (95\% CI, 0.58-0.65). Desille-Gbaguidi et al. [29] also pointed out that survival does not depend on the type of surgery, which was in accordance with our findings. Partial mastectomy ensuring negative margins may act as the primary surgical selection for stage IV patients. However, we should note that the difficulty in acquiring accurate information of grade, tumor size, and number of involved lymph nodes of patients without surgery could result in missing data, especially in the NST group, which could then affect the statistical significance. This result emphasizes the necessity of sufficient assessment for breast cancer patients. According to our data, the number of ST patients with more than 2 metastatic sites was limited, which shows that, in current practice, surgery of the primary tumor is seldom performed in patients with multiple metastatic sites. Through this study, we hope to illustrate that systematic therapy may not be the only choice for PMBC patients, and local surgery may bring survival benefits when performed properly. It is essential and consequential to conduct prospective trials to determine the possible benefits of surgery in PMBC patients, particularly in specific types of patients and in the appropriate way. Given these findings, we believe that our study provides some valuable insights into the treatment strategy of PMBC.

To the best of our knowledge, the biological rationale for supporting ST of primary tumors is that the tumors can act as a continuous resource of malignant cells with metastatic competence and induce immune suppression [30]. In contrast, the levels of antiangiogenic factors or growth factor inhibitors that may be present in primary tumors could be reduced after upfront ST, and accelerated relapse may follow [31]. Thus, further studies should be performed to explain the mechanism of the relationships between them.

We need to acknowledge the limitations of this study. First, we cannot rule out that this retrospective study had a selection bias. For example, the differences of economic status and insurance between different states may result in a certain bias in our results. Second, the SEER database lacks information regarding symptoms, response to therapy, specific type of systemic therapy such as target therapy, the sequential order of treatment, and so on. Furthermore, the median follow-up of this study was not long enough because the data we collected were from 2010 to 2013. Therefore, a long-term prospective investigation should be conducted to draw far more conclusions scientifically.

In conclusion, despite the limitations of the SEERbased study, the results demonstrated that ST for the primary tumor appeared to confer a survival benefit in patients with $\mathrm{PMBC}$ at initial diagnosis. As we observed in our study, ST may contribute to superior outcomes in stage IV breast cancer patients with 1 or 2 metastatic sites and HER2-positive individuals with more than 2 metastatic sites. However, we do not advocate a radical operation procedure for these patients, as it is less likely to improve survival. We conclude that prospective trials are needed to fully evaluate the role of surgery in PMBC.

\section{Acknowledgements}

This work was supported by grants from National Natural Science Foundation of China $(81773093,81472669)$ and a Municipal Human Resources Development Program for Outstanding Leaders in Medical Disciplines in Shanghai (2017BR028).

\section{Statement of Ethics}

The authors have no ethical conflicts to disclose.

\section{Disclosure Statement}

No potential conflicts of interest were disclosed. 


\section{References}

1 Ferlay J, Soerjomataram I, Dikshit R, Eser S, Mathers C, Rebelo M, et al. Cancer incidence and mortality worldwide: sources, methods and major patterns in GLOBOCAN 2012. Int J Cancer. 2015 Mar;136(5):E359-86.

2 Siegel RL, Miller KD, Jemal A. Cancer statistics, 2016. CA Cancer J Clin. 2016 Jan-Feb; 66(1):7-30.

3 DeSantis CE, Lin CC, Mariotto AB, Siegel RL, Stein KD, Kramer JL, et al. Cancer treatment and survivorship statistics, 2014. CA Cancer J Clin. 2014 Jul-Aug;64(4):252-71.

4 Hortobagyi GN, de la Garza Salazar J, Pritchard K, Amadori D, Haidinger R, Hudis CA, et al.; ABREAST Investigators. The global breast cancer burden: variations in epidemiology and survival. Clin Breast Cancer. 2005 Dec;6(5):391-401.

5 Jung KW, Won YJ, Kong HJ, Oh CM, Shin A, Lee JS. Survival of Korean adult cancer patients by stage at diagnosis, 2006-2010: national cancer registry study. Cancer Res Treat. 2013;45(3):162-71.

6 Park JH, Choi IS, Kim KH, Kim JS, Lee KH, Kim TY, et al. Treatment Patterns and Outcomes in Elderly Patients with Metastatic Breast Cancer: A Multicenter Retrospective Study. J Breast Cancer. 2017 Dec;20(4):36877.

7 Thomas A, Khan SA, Chrischilles EA, Schroeder MC. Initial Surgery and Survival in Stage IV Breast Cancer in the United States, 1988-2011. JAMA Surg. 2016 May; 151(5):424-31

8 Tan Y, Li X, Chen H, Hu Y, Jiang M, Fu J, et al. Hormone receptor status may impact the survival benefit of surgery in stage iv breast cancer: a population-based study. Oncotarget. 2016 Oct; 7(43):70991-1000.

9 Ruiterkamp J, Ernst MF, van de Poll-Franse LV, Bosscha K, Tjan-Heijnen VC, Voogd AC. Surgical resection of the primary tumour is associated with improved survival in patients with distant metastatic breast cancer at diagnosis. Eur J Surg Oncol. 2009;35(11):1146-51.

10 Hartmann S, Reimer T, Gerber B, Stachs A. Primary metastatic breast cancer: the impact of locoregional therapy. Breast Care (Basel). 2014 Feb;9(1):23-8.

11 Dominici L, Najita J, Hughes M, Niland J, Marcom P, Wong YN, et al. Surgery of the primary tumor does not improve survival in stage IV breast cancer. Breast Cancer Res Treat. 2011 Sep;129(2):459-65.
12 Hazard HW, Gorla SR, Scholtens D, Kiel K, Gradishar WJ, Khan SA. Surgical resection of the primary tumor, chest wall control, and survival in women with metastatic breast cancer. Cancer. 2008 Oct;113(8):2011-9.

13 Khan SA, Stewart AK, Morrow M. Does aggressive local therapy improve survival in metastatic breast cancer? Surgery. 2002 Oct; 132(4):620-26.

14 Demicheli R, Hrushesky WJ, Retsky MW, Bonadonna G, Valagussa P. Comment to "Effect of primary tumor extirpation in breast cancer patients who present with stage IV disease and intact primary tumor" by G V Babiera, R Rao, L Feng, F Meric-Bernstam, H M Kuerer, S E Singletary, K K Hunt, M I Ross, K M Gwyn, B W Feig, F C Ames, G N Horthobagyi. Ann Surg Oncol 2006;13:776-782. Ann Surg Oncol. 2007 Apr;14(4):1519-20.

15 Rashaan ZM, Bastiaannet E, Portielje JE, van de Water W, van der Velde S, Ernst MF, et al. Surgery in metastatic breast cancer: patients with a favorable profile seem to have the most benefit from surgery. Eur J Surg Oncol. 2012; 38(1):52-6.

16 Neuman HB, Morrogh M, Gonen M, Van Zee KJ, Morrow M, King TA. Stage IV breast cancer in the era of targeted therapy: does surgery of the primary tumor matter? Cancer. 2010 Mar;116(5):1226-33.

17 Rhu J, Lee SK, Kil WH, Lee JE, Nam SJ. Surgery of primary tumour has survival benefit in metastatic breast cancer with single-organ metastasis, especially bone. ANZ J Surg. 2015 Apr;85(4):240-4.

18 Gradishar W, Salerno KE. NCCN Guidelines Update: breast Cancer. J Natl Compr Canc Netw. 2016 May;14(5 Suppl):641-4.

19 Rashid OM, Takabe K. Does removal of the primary tumor in metastatic breast cancer improve survival? J Womens Health. 2014; 23(2):184-8.

20 Glehen O, Mohamed F, Gilly FN. Peritoneal carcinomatosis from digestive tract cancer: new management by cytoreductive surgery and intraperitoneal chemohyperthermia. Lancet Oncol. 2004 Apr;5(4):219-28.

21 Flanigan RC, Salmon SE, Blumenstein BA, Bearman SI, Roy V, McGrath PC, et al. Nephrectomy followed by interferon alfa- $2 \mathrm{~b}$ compared with interferon alfa- $2 \mathrm{~b}$ alone for metastatic renal-cell cancer. N Engl J Med. 2001 Dec;345(23):1655-9.
22 Hu Q, Zhong X, Liu X, Xie Y, Hu K, He P, et al. Resection of primary lesion for patients with metastatic breast cancer: where are we now? Linchuang Zhongliuxue Zazhi. 2018 Jun;7(3):24

23 Barbie TU, Golshan M. De Novo Stage 4 Metastatic Breast Cancer: A Surgical Disease? Ann Surg Oncol. 2018 Oct;25(11):3109-11.

24 Blanchard DK, Shetty PB, Hilsenbeck SG, Elledge RM. Association of surgery with improved survival in stage IV breast cancer patients. Ann Surg. 2008 May;247(5):732-8.

25 Harris E, Barry M, Kell MR. Meta-analysis to determine if surgical resection of the primary tumour in the setting of stage IV breast cancer impacts on survival. Ann Surg Oncol. 2013 Sep;20(9):2828-34.

26 Headon H, Wazir U, Kasem A, Mokbel K. Surgical treatment of the primary tumour improves the overall survival in patients with metastatic breast cancer: A systematic review and meta-analysis. Mol Clin Oncol. 2016 May;4(5):863-7.

27 Rapiti E, Verkooijen HM, Vlastos G, Fioretta G, Neyroud-Caspar I, Sappino AP, et al. Complete excision of primary breast tumor improves survival of patients with metastatic breast cancer at diagnosis. J Clin Oncol. 2006 Jun;24(18):2743-9.

28 Badwe R, Hawaldar R, Nair N, Kaushik R, Parmar V, Siddique S, et al. Locoregional treatment versus no treatment of the primary tumour in metastatic breast cancer: an openlabel randomised controlled trial. Lancet Oncol. 2015 Oct;16(13):1380-8.

29 Desille-Gbaguidi H, Avigdor S, Body G, Ouldamer L. Survival impact of primary site surgery on metastatic breast cancer patients at diagnosis. J Gynecol Obstet Hum Reprod. 2019 Mar;48(3):171-7.

30 Sinha P, Clements VK, Miller S, OstrandRosenberg S. Tumor immunity: a balancing act between $\mathrm{T}$ cell activation, macrophage activation and tumor-induced immune suppression. Cancer Immunol Immunother. 2005 Nov;54(11):1137-42.

31 Retsky M, Bonadonna G, Demicheli R, Folkman J, Hrushesky W, Valagussa P. Hypothesis: induced angiogenesis after surgery in premenopausal node-positive breast cancer patients is a major underlying reason why adjuvant chemotherapy works particularly well for those patients. Breast Cancer Res. 2004;6(4):R372-4. 